\title{
Research on Teaching about Three Dimensional Effect Chart
}

\author{
Huiping Zhang
}

Department of Environmental Art Design, Hebei Institute of Fine Art ,Shijiazhuang, Hebei, 050700, China

Keywords: indoor rendering, 3D design, teaching method

\begin{abstract}
D rendering indoor design is one of the important part of interior decoration design, in order to make students better learning of this course, the need for 3D indoor rendering design course syllabus to make the necessary upgrading. 3D interior design teaching should be to train in the design of the first line which has an independent design capability and can be engaged in the specific design and management of the design personnel as foothold, at the same time also should strengthen the noble moral character, to the human society sense of responsibility, has the innovative spirit and ability, have the consciousness and ability of lifelong learning, etc. The cultivation of the overall comprehensive quality. In higher education, the teaching quality is the life, school characteristics is an advantage. Key in interior design teaching reform pays special attention to the discipline characteristic, further to reform the course system and teaching content. In order to improve the teaching quality, fully meet the needs of the interior design teaching reform.
\end{abstract}

\section{The Introduction of the Problem}

With the development of the social and economic, the demand for design professionals in the field of is diversified, therefore different levels, different types of talents will be welcomed by society. Interior design teaching should be established according to the environmental conditions of oneself and keep its teaching features, to design the teaching aim of talents cultivation, the specifications, should according to the diverse needs of society, a positive and creative response. Therefore, the hospital on the interior design teaching in applied talents for the characteristics of design teaching mode is given priority to, companies involved in curriculum design and project design. Colleges and universities such as interior design professional worker, arts and the sciences compatible. Especially its graphics teaching, engineering and arts two different directions, cultivate the students each have advantages and disadvantages. For partial and partial arts discussed different perspectives of interior design teaching, put forward with pertinence and maneuverability of liberal arts is compatible with the teaching ideas and concrete methods of teaching .Interior design is based on three dimensional space of applied art design categories, therefore in the process of professional learning the teacher not only need to pay attention to training students to have a certain art appreciation ability, image thinking ability and space thinking ability, more attention should be paid to in the experiment teaching can enable students to master their own creative thinking through the graphic language in the form of expression ability. This ability is the future work in the interior design must have one of the basic qualities. Interior design experiment teaching from its essence is a kind of innovation activities, it is under the guidance of theory of interior design, according to certain experimental condition to use technical means to achieve design thinking. Obviously this experimental teaching process is different from the abstract teaching design theory, its task is to make students not only through the experiment means to deepen understanding of knowledge and to express their design ideas, but more important is to let the student to grasp the science the design technique of expression, bold use of new methods to solve practical problems, to cultivate the ability to explore the unknown - innovation consciousness and creation ability [1].

So introducing 3D Max software indoor design experiment teaching is particularly important. 3D Max is interior design professional to offer a course of 3D cad design performance, the main characteristics is to apply the most advanced 3D graphics processing technology in the modern interior design, the height of the emphasis on technology and art together. Students in learning 3D Max software have contact with some basic knowledge of computers, is also the basis of 
systematically study the interior design courses and professional courses, thus has certain basic computer basic knowledge and professional design. At the same time it still has some problems, one of the most major problem has the following several aspects:

Insufficient understanding of 3D Max experiment teaching, many students will be simple to understand for experimental teaching method of 3D Max computer software to study, lead to learning and professional software, learned to interior design professional knowledge and the integration of 3D Max software.

The use of mechanical software: software, through the use of learning can only simple mechanical flexible skilled operating software will not his own design ideas expressed by the method of simple and quick.

The lack of practical experience, because it is the actual production experience, can't make drawings to professional standards. Many students in the process of drawing, for example, due to the understanding of the nature of interior design material deviation, so unable to accurately express through production software3Dmax software, easy to cause the deviation on the vision.

Aiming at these problems, the indoor design adopted in the experiment teaching is the teaching method of the following steps, has received the good effect.

\section{Strengthen the Combination between Production Practice Teaching}

Production in combination with the practice teaching is a basic approach to cultivate practical talents, the teaching process focuses on the mastery of competencies at design and the cultivation of basic skills. Practice teaching can make students focus on the latest situation of the social practice, the contents of professional study closely combined to solve practical problems, truly reflects the theory with practice, let students to practice, improve graduates work ability to adapt. This clearly reflected in the project design of the teaching, thematic design mainly cultivate students for design object, based on various design constraints, to find the best solution. When designing task training content and form, to choose design company or reconstruction projects as the training objects. Training form mainly adopts real topic real done, virtual topic real done two forms. Real topic real done is to put the design project of the various restrictions as to the specific requirements of the selected topic, the reference design workflow and complete the requirement of design problem of the company. Request to track the teaching design company, to student's design proposal, let the students have the opportunity to further design the first line, be familiar with design works of the company. Virtual real do is put the design of the virtual subject in real environment to carry on the design of this kind of topic generally belongs to the redevelopment project, students can conduct site survey, to understand and explore limit design conditions. This method between virtual and reality, in dealing with all kinds of restriction conditions at the same time, students and larger space for the subjective performance, which is very attractive for students. Two forms of training, there is a common feature, is the emphasis on the authenticity of the training subject. Specific environment to carry out the design must be based on reality, and design company involved in increasing the effectiveness of training process, can let students feel some is only to be learned in the field environment of important industry norms, conscious experience and strain method. Use of university-industry cooperation, emphasis on ability training teaching method is not only widely used in the project design course teaching, such as graduation design requires the ability to reflect the comprehensive design course can also be used.

An important link in training practical ability is the design of field research and analysis, students according to their abilities and preferences to select the suitable design object, through the in-depth design of the field investigation, discover and capture one of the effective information, such as site conditions, user characteristics, use function requirements, etc., make it become the starting point for design and put forward the basis of a solution. Interior design course is rich in content, flexible teaching ideas and characteristics of thematic, and should not be restricted teaching field and region; Project design forms, can reflect and reflect the reality of the city, the organic combination of classroom teaching and field teaching, to cultivate students to design the site observation ability, analysis ability and sensitivity. 


\section{Combined with Professional Background, Firmly Grasp the Basic Knowledge}

Combining with the characteristics of interior design professional. Before teaching 3D Max software, lead the students to review the first interior design related courses, such as interior design drawing standards, the principle of color science, space composition, etc., so that the students in the study of the interior design at the beginning of 3D Max learning with other professional 3D Max, 3 D Max interior design professional background.

Highlight the focus of the 3D Max software function. Teaching in the first 3D Max software overview of a whole, make the students understand the main function of $3 \mathrm{D}$ Max, and combining with the characteristics of interior design professional, more closely related to every part of the interior design. To deal with the complicated interface and function of $3 \mathrm{~d}$ Max I will it summarized into four main parts, respectively is: the model of the parts, material, lighting and rendering part. After such summary highlights the focus of the 3D Max, the original complex 3D Max function system simplification, immediately, the students can be sorted out from the complicated and messy situations. Then one by one for each part carefully.

Clarify complex 3D Max software interface. In the face of complex 3D Max software interface system, combining the knowledge of computer software and graphics, 3D Max software can be divided into four main areas: tool area, the menu area, view area, the working area. Make the complex 3D Max software interface system is simple and clear, easy to students to master and operate.

Avoid blind pursue advanced version. With computer technology becoming more updates, 3D Max software also gradually upgrade, in order to avoid blindly pursue high version in the learning process, students ignore the learning of basic knowledge of 3D Max, I insist to use 3D max8.0 in the experimental teaching Chinese, the purpose has two aspects: one is the 3D max8.0 Chinese version is easy to be a scholar to master and use, also easy to install and manage, and now many design firms are also used in great quantities, not eliminated. In addition, tell the students to learn 3DMax software technology for interior design student just means rather than aim, don't blindly comparing high version, master the basic knowledge is the most important.

\section{Making Use of Actual Project, Cultivate the Students' Team}

Spirit and learning ability consciously taught in full 3D Max tools, command and operation method, I will be done by your own in the actual fusion in the experimental teaching of specific projects, on the one hand, through the actual to the actual operation of the project, so that the students can software and interior design theory course organic integration, deepen the understanding of theory course. Students in the process of experiment, on the other hand, to understand the actual project design and production processes, and industry norms, the figure to compare the use of flexible software, avoid after leaving the classroom learning, will not be able to drive software. According to the requirements of actual work at the same time, the complete project is divided into several parts to each design each member of the team, let them simulate real environment collaboration, cultivate their team spirit of cooperation. In addition, exercise the students practice found that the problem, problem-solving ability, improve the effect of the experimental teaching. Teachers are mainly from the traditional teaching into coaching is given priority to, students from passive learning to autonomous learning. So that "lets the student as the main body of learning, the teacher is responsible for the comprehensive teaching, break the traditional teaching model of teacher turnkey package, efforts to build the atmosphere that gives a kind of autonomous learning" into reality [2]. Especially interior design experiment teaching such courses, more emphasis on students' practical ability and the ability to solve problems, so it is necessary to break the traditional teaching in the experiment, the mode of operation of the lack of actual project, the use of multimedia based advanced experiment teaching means, the classroom to the students, make students become the main body of the class, the teacher is only responsible for the comprehensive guidance, become the class participants. Let the students of every creative operation to promote and sublimation. 


\section{The Collective Teaching and Combining the Tutorial}

In the process of teaching, I adopt the method of combination of collective teaching and individual counseling, use modern multimedia projection equipment and computer synchronization transmission equipment, so that the students can see teachers every step of the operation. This method can save the teacher a lot of time, for the individual coaching. [3]

Through multimedia projection equipment and computer synchronization transmission equipment to collective teaching, the students try to slow down the pace of teaching, especially the teaching of specific project operation and software complex command tool, but also described step by step, at the same time using computer synchronous transmission equipment will be teaching content written electronic transmission to the students, for students to review after class

Each student's ability to accept, especially interior design student most is set, the fine arts for some complex 3D Max software tool, the understanding of the command or instance level is relatively lower, so there are some ability to accept a slower students is more difficult to understand, then I'm through the students' body temperature, according to different situation of each student to tutorial. Counselling can increase the teacher and the students' communication, easy to master by the teacher each student's specific conditions, conducive to the teacher for each student's specific

The Characteristics of Art Design in Higher Vocational Colleges Students Groups. In the student groups, art design class in higher vocational colleges students have their own characteristics, and that their education experience of the intimate relationship.

1. Art design class in higher vocational colleges students academic foundation is weak, generally less subjective initiative of learning. Most art design in higher vocational colleges students who are weak, because feel there is no hope for college, some of them are during the full-time ordinary high school, chose to paint this shortcut way, to their own university dream; While others can only choose a career high school or vocational school to learn, vocational high school adhere to the employment as the guidance, to serve the local economy rather than to get into college as the main purpose. This kind of academic and social practice teaching model of combining resulted in vocational high school students than ordinary high school students a solid academic foundation, and their learning habits and learning behavior has its own characteristics, there are some negative forms, such as learning discipline is not strong, weak concept of time, etc.

2. Have certain experience in social activities, beginning ability is strong, the more interested in social practice. Vocational education of basic course teaching and social practice of combining the education mode, make the practice of higher vocational students have more opportunities and free space. They work in practice and in the process, to a certain degree of understanding and adapt to the social environment, the beginning ability also strengthened, these are better than that of most undergraduate students after their entry into the university.

3. The character diversification, but thought is relatively simple. Higher vocational students are middle school students poor academic performance, at the present stage our country middle school with the raising of the university for the purpose of teaching mode, under the influence of their long-term shrouded in school under the shadow of "excellent" same age students, combined with the social and family of pressure to them, to avoid to make them form the impulse, paranoia and personality traits. At the same time, in order to prove himself, they tried to from different from the "learning" "elsewhere" get the opportunity to realize self creates in their words and deeds, dress and behavior way too much emphasis on many aspects, such as his own personality, even to an extreme, make them unable to communicate effectively with others in some way, to a certain extent, lack of team spirit.

Similarly, it also creates the way they look at problems is one-sided and simple, emphasizes the practical significance without the long term, can't see a problem from the view of contact. [4]This is reflected in the learning without learning enthusiasm and subjective initiative, on the content of the class the teacher practice while learning, repeatedly does not pay attention to the accumulation of knowledge and learning, so had not fully grasp common system.

Cultivate Professional Talents for the Enterprise, the Social Position. As the city of Hangzhou government focus on fostering higher vocational colleges, should be the development of 
Zhejiang economy, medium for Zhejiang enterprises to train skilled applied art design talents. This professional is the main training goal for decoration design, display design, rendering design companies, construction companies, supervision company, related building decoration sector to cultivate professional talents, engaged in construction decoration design, display design, rendering of art and design, environmental art design, decoration, decoration engineering supervision, construction and management in the field of engineering budget preparation work, also can be engaged in building decoration engineering units of all kinds of business management.

Talent cultivation of higher vocational colleges and his brother the same professional dislocation development, cultivate our characteristics. On the one hand, the professional orientation in small and medium-sized enterprise interior decoration design jobs; Demand for small and medium enterprises, on the other hand, the characteristics of "a hillock pluripotent" interdisciplinary talents cultivation model is put forward, namely: in view of the small and medium-sized building decoration enterprise, with the help of our art base advantage, make the students familiar with and master the use of 3 ds Max software and related plug-ins, and familiar with all kinds of decorative materials, train to become interior design + rendering design talents.

The Teaching Method of Upgrading. With the development of The Times, old teaching method is not suitable for students' learning. So it is necessary to find a reasonable effective and practical teaching methods, so that the students can quickly grasp some real knowledge and skills. In the face of the traditional teaching methods and effective teaching methods are compared. [5]

The traditional teaching methods. Are based on the traditional teaching method, has emerged in the late $1990 \mathrm{~s}$, 3Dsmax step of rendering and rendering process division of design company. The production process in the major of higher vocational colleges in $3 \mathrm{~d}$ rendering indoor design course teaching widely popular. The production process begins to get the working drawing, through modeling, lighting, stick materials, rendering, post-processing, the three steps to be short of one cannot. For rendering design company, this is three steps through three producers are different

Service division of labor, assembly-line team to complete, so as to design a good drawing. For the maker is proficient in the software operation ability, aesthetic ability and art accomplishment has a very high requirements. However, for students just beginning this software, if you want to learn, good in 3D Max software, is not easy, students often meet with difficulties can't stick to it.

Teaching experience for many years to make myself feel deep, teachers tend to put the different stages of its production process as priorities for teaching.

(1) (key): modeling in the teaching process of the past, modeling is classified as is one of the focus of the whole rendering process. Model as "skeleton" is the human body, the stand or fall of model making, directly influence the rendering effect. Modeling for many students is relatively difficult to master, because the process of modeling is a complicated chore. In whole and interior space, there are large and small model needs to be created, the amount of time also is more, the students in this aspect of learning process, often appear to be more chaotic, boring, boring, can not perserve learning state, lead to affect the process behind the phase of the study enthusiasm.

(2) lights (key): in 3D Max software is to simulate the real lights lighting lighting, through the use of light in the scene, simulate the real world of different kinds of light source, the objects in the scene lighting, through vivid light effects enhance the realistic scene. In the scene lighting is mainly rely on 3D Max software's own standard lighting and photometric lights lights of two types of lighting. Most of the students in the process of learning to play lights, usually do not good, there are three reasons: first, the student is not good for all types of lighting parameters setting grasp; Second, the student to the scene of the auxiliary lighting control is bad, I don't know where the lamp, where shouldn't play lamp, lack; Third, the student to the details of life observation is not enough, perception is not high, lead to can't reflect the real scene lighting effects. In these areas, as long as the teachers taught this course will have deep feelings. How to solve this problem, also always peers distress, how to make the students to better grasp the knowledge, is also the goal of peers think for exploration.

(3) posted material (key): generally speaking, in the material aspect, the majority of students can master basic kinds of commonly used material, however, can edit the real texture students little little. 
Because it requires the students a good understanding and mastering all kinds of commonly used material properties, and master all kinds of methods of editing of material, it is very critical. This phenomenon also reflects the student to the details of life observation is not enough, insufficient understanding of the characteristics of all kinds of things, perception is not high.

(4) rendering: using 3D Max software in the default scanline renderer to apply colours to a drawing gives figure, students can grasp well in this aspect and application, because the renderer of parameter Settings is relatively simple, not a lot of places need to adjust the Settings. In general, when the map is finally out, need to adjust the public section of the output size and rendering output two places.

(5) post-processing: this learning process stage, is mainly to teach students using another powerful image processing software Photoshop (hereinafter referred to as "PS") for post-processing. PS software is powerful, but it is late for rendering process, the function is not used a lot, normally just photoshop software for rendering the color balance, hue, saturation and brightness contrast adjustment and labeled as ornaments processing in rendering. Because before this course, students have studied the PS software class, so students learn to these knowledge is relatively simpler, can grasp well. It is worth noting that if not enough students create the rendering effect of real right, the PS post-processing is meaningless. To see rendering the pre-production is critical.

Effective teaching methods. Effective teaching methods are based on my years of teaching experience and practice experience, the teaching method is different from the traditional teaching method, the rendering process no change, just focus on the production process to make the adjustment. In teaching, in order to let students interested in this course, from passive learning into active learning, in promoting students' learning self-confidence plays a very important role. Made in $3 \mathrm{~d}$ rendering indoor three steps, the process simplified and application of content on the teaching of modern advanced science and technology senior VRayAdv renderer plug-in. Through the organic combination of the two, make the teaching method is more direct, more simple, let the students more interested in learning more easy to understand, and more effective, so as to improve the teaching quality and teaching effect, in this way can we truly achieve the goal of teaching.

The following about the author in the process of practice teaching in recent years to get a little experience and inspiration:

(1) modeling: complex cumbersome process, difficult to learn if you want to learn good modeling, school teaching these lessons, alone is difficult to master good. So, if students don't study the modeling? Through this paper expounds the importance of a modeling. Then modeling aspects of learning should be repositioned, positioning factors depends on two things: first, clear the purpose of this course, in the role of this major, it's not hard to see from the course name, the main content of the course is aimed at rendering design, the design of interior space that can shrink the modeling range to interior space modeling. Now that are some of the modeling, interior space is the interior space of the surface modeling from all walks of life, indoor surface is mainly from all walks of life from the ground, end face and surround close together, as long as the students create a simple interior space model framework. Second, is to make full use of network resources in the interior space needs of the furniture, sanitary ware, search and download decorations such as model, and delicate, fashion, generous, elegant, rich and rich personalized all kinds of beautiful models. This is both convenient and save time, still can improve the students' learning enthusiasm and learning efficiency. In a word, the author think that modeling is difficult to grasp, the more amount of time. If want to engaged in this work in the future, at ordinary times is best form the good habit of accumulation, collection model. Because in the future work does not allow us to spend a lot of time to model, so the collection of data is drawing must be prepared before.

(2) lights (key): in the scene lighting in addition to by 3Dmax own standard lamps and lamp photometric lights, also use large amounts of the VRay lights to light. Mostly used in the process of scene lighting standard target parallel light to simulate the sun light, there are a few people will use VRay lights in VR sun; And the canister light, shoot the light in the scene, droplight, such as light and shadow, use the photometric lights in the target or free light photometric Web to simulate the real lighting effects, photometric Web will use to the different kinds of light field in network file; 
Scenario also use large amounts of VRay light plane of VR lighting light source to simulate the light and the light, the parameter Settings of these lights is relatively simple, and easy to master, and can achieve good results. , of course, only by the use of these lights are not enough, also must want to have a good lighting train of thought, the author thinks that to combine the real life situation to make the light better. In other words, where there is a lamp is where to play. This is the most effective way to directly. Producers know that light transmission has a certain distance, is not enough to only rely on the main light source. The use of natural light as the main light, must pay attention to the degree of exposure, determined the main light source and then is the artificial light. There is no light in some places the design, but in order to balance effect on performance, we will add light on the role of mood regulation. Light supplement can build atmosphere, can also be illuminated space. Such as: many students asked the author to such a problem, not enough white metope is why? I think the reason is not seize the color contrast, suggested by point blue on white material, this makes metope white point. For example: space is light yellow, you can add some blue metope, let the white balance; Vice is to seize the yellow, and blue combine the balance. To sum up, a light, you don't to others the lights of the parameters of copying, for beginners to learn from is allowed, but must have the analytical thinking, want to more a few why, in this way can help to improve the level of their own.

(3) posted material (key): at present, a lot of people through the network resources to download some material, it is very convenient. It is important to note that materials and textures are complementary to each other, if you want to edit the real texture, need a good understanding and mastering all kinds of commonly used material properties, and master all kinds of methods of VRay material editing of material, it is very critical. The author thinks that VRay material edit it properly or not, directly affects the actual effect.

(4) rendering (key): a flush after many times of test rendering, in order to achieve satisfactory results. Rendering, after the completion of a record to modify content, don't after press F9 to remember and things didn't change. Under normal circumstances, the model built after linear render time, look. Model to delicate, don't face to remove it. Then lights, set the VRay renderer test rendering parameters, rendering time, stick good texture rendering it again. Best again according to their own habits change good directly set VRay renderer render parameters, the figure out of the big picture.

(5) post-processing: in this part of the requirements with the traditional teaching method is consistent with the mentioned part. If producers PS post-processing level is very high, it can save a lot of things. I normally just photoshop software to adjust curve, color balance, hue, saturation and brightness contrast this several parts. Many people will leave decorations on PS, this is a personal habit. If is not very proficient in photoshop software, then use less as far as possible the PS to deal with. PS is used to change the visual feeling, in spite of this, the author think PS post-processing or essential link.

Interior design is the labor, the arts, the sciences compatible discipline, discipline span is big, the talents training target and way are different from other disciplines. To conform to the requirements of talents training target, teaching methods to meet the needs of professional development must be to study teaching system.

On the system, open interior design professional vocational colleges exists partial engineering and the arts. Partial engineering professional interior design based on a general engineering colleges and universities, the increase in the curriculum "engineering drawing", "housing architecture" and "engineering mechanics" engineering course, at the same time in teaching emphasize the standardization, operability, and safety. The quadrature in the compasses in colleges and universities graduates, field practice ability. Design scheme is compared commonly specifications, usually has a strong operability. But their design works of imagination and artistic appeal. Partial arts major general because art college offers interior design. On the teaching emphasis on "sketch", "color" the fine arts curriculum, emphasis on visual effect, creativity and imagination. This kind of university graduate student active float in the sky, full of passion. Design solution generally show a strong emotion and individual character, but in the normative and scheme of the figure of a slight 
lack of operability. Same profession has so different education effect, find out takes both advantages of a system should be set up interior design professional vocational colleges must be thought.

Interior design is a visual art design that is the core goal is graphics. Here graphics should cover engineering drawing, sketch, color, composition, etc. Interior designer by graphics to owner or the construction personnel to express their design intent. Therefore, research on teaching system should be put aside complex program later design theory and construction management, professional graphics system is emphatically discussed.

Interior design teaching should be to train in the design of the first line which has an independent design capability and can be engaged in the specific design and management of the design personnel as foothold, at the same time also should strengthen the noble moral character, to the human society sense of responsibility, has the innovative spirit and ability, have the consciousness and ability of lifelong learning, etc. The cultivation of the overall comprehensive quality. In higher education, the teaching quality is the life, school characteristics is an advantage. Key in interior design teaching reform pays special attention to the discipline characteristic, further to reform the course system and teaching content. In order to improve the teaching quality, fully meet the needs of the interior design teaching reform, the reform must be in the following aspects.

\section{Conclusion}

Above all, the teaching method should keep improving, and keep pace with The Times. Invariable teaching methods is difficult to develop society, industry, enterprise need high skilled talents. Only come to the conclusion that better conforms to the professional development of teaching methods, to promotes the development of interior design professional, to cultivate higher vocational art design major students' practice ability. In this way can make students gain a foothold in the fierce competition. That is to say, the teacher whether to adopt better teaching methods, directly affect the students have strong ability of practical operation, the ability is related to student employment, school enrollment and the key factor for the survival and development.

\section{References}

[1] Li Weihua. On the basic knowledge of computer architectural rendering [J]; Shanxi architecture; 2003 (05)

[2] Xu Fei. 3DMAX indoor rendering map rendering [J], Journal of Panyu Polytechnic Institute; $2005(01)$

[3] Han Yu. Experience type teaching, the landscape design course teaching practice research [D]. Nanjing: Nanjing College of Art. 2012

[4] Suo Liya. The exploration and research of "project engineering room" in the teaching of interior design specialty in Higher Vocational colleges. Journal of Chongqing Education College. 2012 (6): $127-128$

[5] liu Chun-bo . Analyses of landscape environmental art [J]. The Young Writer. 2010 (18) 